1 Escola de Filosofia e Teologia Afrocentrada (Estaf) - Porto Alegre (RS), Brasil.

oba.olorioba@gmail.com

2 Escola de Filosofia e Teologia Afrocentrada (Estaf) - Porto Alegre (RS), Brasil.

jaypjesus@hotmail.com

3 Universidade Federal do Rio Grande do Sul (UFRGS), Programa de Residência Integrada Multiprofissional em Saúde Mental Coletiva - Porto Alegre (RS), Brasil. dani.scholz@hotmail.com

\section{Paradigma da afrocentricidade e uma nova concepção de humanidade em saúde coletiva: reflexões sobre a relação entre saúde mental e racismo}

The afrocentricity paradigm and a new humanity conception in public health: reflections on the relationship between mental health and racism

Míriam Cristiane Alves', Jayro Pereira de Jesus ${ }^{\mathbf{2}}$, Danielle Scholz ${ }^{\mathbf{3}}$

\begin{abstract}
RESUMO Este ensaio tem por objetivo fornecer elementos para o estudo da relação entre saúde mental e racismo com vistas a inaugurar uma nova concepção de humanidade em saúde coletiva baseada no paradigma da afrocentricidade. As reflexões partem da problematização da existência de dois paradigmas civilizatórios que constituem a sociedade brasileira e que produzem subjetividades: o paradigma ocidental e o negro-africano. No campo da saúde coletiva, o desafio que se apresenta é o de inaugurar um novo processo de escuta e reconhecimento dos diferentes valores e práticas civilizatórias, rompendo com o olhar preconceituoso e racista que ainda hoje é lançado às pessoas de ascendência africana.
\end{abstract}

PALAVRAS-CHAVE Saúde mental; Racismo; Saúde pública; Psicologia social.

ABSTRACT This essay aims to provide elements for the study of the relationship between mental health and racism in order to cast a conception of humanity in public health as from the afrocentricity paradigm. These reflections depart from problematizing the existence of two civilizational paradigms that form the Brazilian society and produce subjectivities: the Western paradigm and the black-African one. In the public health field, the challenge concerns the launching of a new process of listening and recognition of different values and civilizational practices, breaking with the bigoted and racist sight still turned against African descendent people.

KEYWORDS Mental health; Racism; Public health; Psychology, social. 


\section{Introdução}

O Brasil é um país que recebeu contribuições civilizatórias de vários grupos étnico-raciais, dentre os quais destacam-se os povos de ascendência africana, que prestaram incomensuráveis e substanciais contribuições a este Estado, produzindo riquezas com suas mãos, porém, sem acesso aos bens por eles produzidos. Essa contribuição na economia, na arquitetura, nas artes, na saúde, dentre outras áreas do conhecimento, continua a apresentar na contemporaneidade profundas assimetrias sociais e étnico-raciais.

As assimetrias étnico-raciais possuem como pano de fundo o processo de colonização que aviltou a humanidade dos povos africanos na diáspora negra, e que se atualiza no contemporâneo por meio da colonialidade que, de acordo com Quijano (2010), se expressa na negação de direitos e de valores civilizatórios de povos tradicionais, cujo olhar preconceituoso e racista lançado a eles rompe relações e identidades civilizatórias e, consequentemente, produz 'desagência' como fator de vulnerabilidade da população negra mediante a vivência de uma humanidade de concessão e subalterna, que, consequentemente, leva a sofrimento psíquico. Para Asante (2009, P. 95) a desagência pode ser encontrada "em qualquer situação na qual o africano seja descartado como ator ou protagonista em seu próprio mundo". A desagência, portanto, refere-se a uma incapacidade de "dispor de recursos psicológicos e culturais necessários para o avanço da liberdade humana" (ASANTE, 2009, P. 94), produzindo, assim, uma humanidade de concessão e subalterna e, ao mesmo tempo, um pseudopoder ao povo negro, que acaba por reforçar sua existência a serviço da colonialidade.

Conforme Silva (2005) negros e negras vivenciam na sociedade brasileira um estado de tensão emocional permanente, oscilando entre sentir-se ora perseguidos e ora perseguidores. $\mathrm{O}$ racismo incorporado às estruturas sociais causa acessos desiguais para negros e não-negros, naturalizando-se e tornando-se imperceptível ao conjunto da sociedade. Ainda segundo Silva (2005), tais desigualdades acabam sendo erroneamente avaliadas como ato persecutório por negros e negras no conjunto das relações sociais, afetando, desse modo, a subjetividade e a construção da identidade, o que, mais uma vez, contribui e reforça a produção de uma existência de 'ser negro e negra' pautada e a serviço da colonialidade. Conforme Ferreira e Camargo (2011, P. 387), "as pessoas negras, submetidas a um processo de desvalorização constante", alimentada pela colonialidade, "tendem a se identificar com uma minoria estigmatizada", constituindo um "segmento da população brasileira que talvez mais sofra o efeito da discriminação e do preconceito, sempre encobertos por frases e gestos ambíguos".

A colonialidade é um dos elementos constitutivos de um padrão mundial eurocêntrico, que consolida uma "concepção de humanidade segundo a qual a população do mundo diferencia-se em inferiores e superiores, irracionais e racionais, primitivos e civilizados, tradicionais e modernos" (QUIJANO, 2010, P. 86). Ela incide histórica e secularmente nas produções científicas, invisibilizando o conhecimento de povos tradicionais, de forma a reificar um modo de compreender o mundo em detrimento de outro. Ou seja, privilegia-se um referencial teórico-prático que segue a racionalidade da ciência moderna, reafirmando a cultura hegemônica em detrimento da considerada subalterna.

Um exemplo de colonialidade é o próprio racismo institucional que penetra, participa e se naturaliza na cultura da organização/ instituição como um elemento estruturante das relações entre pessoas e instituição, de modo que o trabalhador acaba contribuindo com a manutenção da colonialidade na esfera pública. Para Silva (2005), o racismo institucional é determinante de iniquidades no acesso aos equipamentos sociais e gera conflitos nas relações inter-raciais, provocando 
desigualdades no modo de inserção e impactos perversos na subjetividade de grupos racialmente oprimidos. A manifestação do racismo por meio de "preconceitos, estereótipos e discriminação é gerador de situações de violência física e simbólica" (SILVA, 2005, P. 130) e, sobretudo, de violência civilizatória, que, ainda segundo a autora, "produzem marcas psíquicas, ocasionam dificuldades e distorcem sentimentos e percepções de si mesmo" (SILVA, 2005, P. 130).

$\mathrm{O}$ descentramento existencial produzido nas subjetividades individuais e coletivas por meio da distorção de sentimentos e da percepção de si impede uma análise crítica sobre os efeitos da colonialidade nas relações de poder, de modo a contribuir com a manutenção das iniquidades civilizatórias, ou seja, com a negação da existência de diferentes ontologias, epistemologias e éticas do viver no mundo.

Este artigo tem por objetivo fornecer elementos para o estudo da relação entre saúde mental e racismo com vistas a inaugurar uma nova concepção de humanidade em saúde coletiva baseada no paradigma da afrocentricidade. Trata-se de um ensaio temático cujas reflexões e discussões partem da problematização da existência de dois paradigmas civilizatórios que constituem a sociedade brasileira e que, consequentemente, produzem subjetividade no seio do extrato social: o paradigma ocidental e o negro-africano.

\section{Paradigmas}

As discussões em torno do conceito de paradigma, no campo científico, têm na obra de Kuhn (2006) 'A estrutura das revoluções científicas' um importante marco. Já em seu prefácio, o autor salienta:

considero 'paradigmas' as realizações científicas universalmente reconhecidas, que, durante algum tempo, oferecem problemas e soluções modelares para uma comunidade de praticantes de uma ciência. (KUHN, 2006, P. 13).
Kuhn define, ainda, que esse conceito possui dois sentidos:

De um lado, indica toda a constelação de crenças, valores, técnicas etc. partilhadas pelos membros de uma comunidade determinada. De outro, denota um tipo de elemento dessa constelação: as soluções concretas de quebra-cabeças que, empregadas como modelos ou exemplo, podem substituir regras explícitas como base para a solução dos restantes quebra-cabeças da ciência normal. (KUHN, 2006, P. 220).

Enquanto Kuhn (2006) discute o conceito de paradigma como parte de comunidades científicas, Morin (2002B; 2007) amplia esse conceito ao alegar que a ele subjazem visões de mundo partilhadas pelas comunidades científicas, embora não se limitando a essas. Para Morin (2007, P. 59) "a palavra paradigma é constituída por certo tipo de relação lógica extremamente forte entre noções mestras, noções-chave, princípios-chave". O autor define que um paradigma contém os conceitos ou as categorias fundamentais para sua inteligibilidade e, a um só tempo, o tipo de relações lógicas de atração/ repulsão entre elas. E assevera que "os indivíduos conhecem, pensam e agem segundo os paradigmas inscritos culturalmente neles", de modo que os sistemas de ideias "são radicalmente organizados em virtude dos paradigmas” (MORIN, 2002B, P. 261). Nessa perspectiva, por paradigma civilizatório entendemos um conjunto de pressupostos, concepções, valores, crenças, saberes e práticas compartilhadas por um grupo de pessoas, e que transcende os limites geográficos onde vivem, que dão vivacidade e organização a um modo de observar, agir e compreender o mundo.

Para conceituar paradigma civilizatório ocidental, partimos das discussões provocadas por Santos (2002) e Morin (2007). Para Santos (2002, P. 10), a racionalidade da ciência moderna constrói o que chama de "Paradigma Dominante", ou seja, um "modelo totalitário" de observar e compreender o mundo, na medida em que "nega o caráter racional a todas as formas de 
conhecimento que não se pautarem pelos seus princípios epistemológicos e pelas suas regras metodológicas". Esse paradigma pressupõe a separação entre ser humano e natureza; visa a conhecer a natureza para dominá-la e controlá-la; assenta-se na redução da complexidade; possui como pressupostos a ordem e a estabilidade do mundo. Morin (2002A; 2003; 2007), ao trabalhar com a ideia de "paradigma simplificador', afirma que ele põe ordem no universo, expulsando dele a desordem; busca a eliminação da irreversibilidade temporal e de tudo o que é eventual e histórico; atua no isolamento/separação do objeto em relação ao seu contexto; pressupõe a separação entre o objeto e o sujeito que o percebe/concebe; reduz o conhecimento do todo ao conhecimento das partes; vê apenas o uno ou o múltiplo, não conseguindo ver que o uno pode ser ao mesmo tempo múltiplo; reduz o conhecimento ao que é mensurável, quantificável, formulável, negando e condenando todo o conceito que não possa ser traduzido por uma medida.

Não obstante, o paradigma civilizatório ocidental também se constitui a partir de conceitos e pressupostos do capitalismo. Este, para manter sua hegemonia desde o início da modernidade, pressupõe a contínua concentração de capital; a crescente expansão geográfica sem limites; o direito de propriedade privada de quaisquer bens; e o poder ideológico, cuja relação de confiança "explica a pacífica aceitação de qualquer espécie de poder: político, militar, econômico, familiar ou religioso" (COMPARATO, 2011, P. 270).

No que se refere ao paradigma civilizatório negro-africano, para conceituá-lo, dialogamos com o 'paradigma afrocêntrico' proposto por Mazama (2009) e Asante (2009). A ideia afrocêntrica, segundo Asante (2009, P. 93), refere-se à "proposta epistemológica do lugar", ou seja, tendo sido os africanos e afrodescendentes (no continente africano ou na diáspora) "deslocados em termos culturais, psicológicos, econômicas e históricos”, qualquer análise e compreensão de suas condições de vida deve ser feita a partir de uma "localização centrada na África e sua diáspora". Dito de outro modo, essa análise e compreensão precisam ser feitas a partir da epistemologia e de elementos civilizatórios do complexo cultural africano.

A afrocentricidade é entendida como

um tipo de pensamento, prática e perspectiva que percebe os africanos como sujeitos e agentes de fenômenos atuando sobre sua própria imagem cultural e de acordo com seus próprios interesses humanos. (ASANTE, 2009, P. 93).

O cerne desse paradigma, portanto, está na afirmativa de que os africanos devem "operar como agentes autoconscientes" de sua história, cuja autodefinição positiva e assertiva deve partir da "cultura africana" (MAZAMA, 2009, P. 111).

Nessa perspectiva, tendo em vista que "qualquer ideia, conceito ou teoria, por mais 'neutro' que se afirme ser, constitui o produto de uma matriz cultural e histórica particular" (MAZAMA, 2009, P. 111), compreende-se que o paradigma civilizatório negro-africano é constituído pelo conjunto de elementos do complexo cultural africano que inscreve em território brasileiro uma dinâmica civilizatória (LUZ, 2000; SANTOS, 2008; SODRÉ, 1988) mesmo diante do paradigma dominante. É constituído por um sistema de valores, crenças e ideias que constrói um modo específico de observar, agir e compreender o cosmos em suas dimensões visível e invisível, e que estabelece uma ética e uma estética para o viver coletivo, fazendo com que seus limites não coincidam com a dimensão geográfica do continente africano.

\section{Por uma concepção de humanidade afrocentrada em saúde coletiva}

A colonialidade atualiza e reforça os antagonismos criados pelo sistema colonialista, e as instâncias de poder do estado democrático de direito reforça a colonialidade por meio de uma 
discussão superficial e racializada, impregnada no conceito de diversidade. Discussão essa que, por sua vez, é alimentada por um sistema de distinções visíveis e invisíveis que constituem a noção do que é 'ser humano' na sociedade eurocentrada, de modo que as invisíveis fundamentam as visíveis, como diria Santos (2010B) quando discute o pensamento abissal:

As distinções invisíveis são estabelecidas através de linhas radicais que dividem a realidade social em dois universos distintos: o universo 'deste lado da linha' e o universo 'do outro lado da linha'. A divisão é tal que 'o outro lado da linha' desaparece enquanto realidade, torna-se inexistente, e é mesmo produzido como inexistente. Inexistência significa não existir sob qualquer forma de ser relevante ou compreensível. (SANTOS, 2010B, P. 32).

Fala-se, portanto, de um não existir, de uma não existência do 'ser humano africano/africana' na diáspora negra produzida pelo colonialismo e atualizada pela colonialidade. Afinal, a característica fundamental do pensamento abissal discutido por Santos (2010B) é a impossibilidade da copresença dos dois lados da linha - do lado de cá e do lado de lá, tendo como pressuposto, como define Dussel (2007, P. 76), a "universalidade abstrata".

Assim, a visibilidade do que é discutido na ótica dos direitos humanos está assentada na abstrabilidade e invisibilidade de algumas humanidades, como, por exemplo, a humanidade africana. Afinal, na humanidade abstrata e invisível, para reforçar a violência impetrada no "outro lado da linha" pelo colonizador,

não há conhecimento real, existem crenças, opiniões, magia, idolatria, entendimentos intuitivos ou subjetivos, que, na melhor das hipóteses, podem tornar-se objetos ou matéria-prima para a inquirição científica. (SANTOS, 2010B, P. 34).

Portanto, a completa estranheza dos conhecimentos e práticas produzidos "do outro lado da linha” conduziu à negação da natureza humana de seus agentes e a consequente desagência dos mesmos, o que, por sua vez, produz a sub-humanidade, a humanidade de concessão e subalterna no contemporâneo. Santos (2010B, P. 39) afirma que "a negação de uma parte da humanidade é sacrificial, na medida em que constitui a condição para a outra parte da humanidade se afirmar enquanto universal", ou seja, como a única humanidade real e dententora das próprias prerrogativas existenciais.

Segundo Mignolo (2013), o conceito de direito constitui-se como ponto importante da racionalidade moderna e, embora provenha do direito romano e da teologia, falando-se de cristãos ocidentais, foi somente a partir das terras e dos agentes do Novo Mundo que o direito entrou em um cenário desconhecido até o momento. Ou seja, produziu-se o direito dos povos e nações, conferindo aos indígenas, por exemplo, o direito de 'ser agente' ou constituir nações. No entanto, o problema é que este conceito está impregnado do pressuposto de inferioridade do não europeu, carregado, ainda, do pressuposto de que mulheres, crianças, indígenas, negros, povos tradicionais, por exemplo, necessitam de seres superiores para cuidarem deles. $O$ conceito de humanidade para a racionalidade moderna, cristã e ocidental é igual a homem, de modo que os direitos são seletivos. Portanto, ainda segundo o autor, esse direito humano não é nem para mulheres europeias, tampouco para mulheres e homens não europeus.

Não obstante, a descolonização dos direitos humanos começa por descolonizar o conceito de humanidade e de humano, ou seja, deve-se abandonar a ideia universal de humanidade imposta pelo paradigma ocidental, cuja noção de humano está calcada no ideal de homem branco, heterossexual e cristão (MIGNOLO, 2013). O conceito de humanidade necessita ser reconstruído na beleza e na incontrolável diversidade da vida, do mundo e dos conhecimentos (MIGNOLO, 2013). Assim, a tarefa que se apresenta é a do 
reconhecimento do que Santos (2010A, P. 543) chama de "diversidade epistemológica do mundo", atentando-se para o "fascismo epistemológico". $\mathrm{O}$ autor salienta que $\mathrm{o}$

fascismo epistemológico existe sob a forma de epistemicídio, cuja versão mais violenta foi a conversão forçada e a supressão dos conhecimentos não ocidentais levadas a cabo pelo colonialismo europeu. (SANTOS, 2010A, P. 544).

Como contraponto a esse 'epistemicídio', Santos (2010A) propõe a "ecologia dos saberes", ou seja, a tentativa de minimizar ao máximo a assimetria entre diferentes saberes. A diferença epistemológica entre os saberes só poderá ser minimizada por meio de comparações recíprocas entre eles na "busca de limites e possibilidades cruzadas". A proposta que o autor faz sobre a "ecologia dos saberes" se refere a uma "epistemologia da douta ignorância", isto é, levar ao máximo para a consciência a incompletude de cada saber por meio do "trabalho de tradução" - procedimento de busca de proporção e correspondência entre os saberes (SANTOS, 2010A, P. 544). Ou seja, "um procedimento capaz de criar uma inteligibilidade mútua entre experiências possíveis e disponíveis sem destruir a sua identidade", que se contrapõe a uma teoria geral que procura dar conta da diversidade de experiências sociais (SANTOS, 2006, P. 779).

Considerando o conceito de humanidade e humano imposto pelo paradigma ocidental e o epistemicípio levado a cabo pelo colonialismo europeu, torna-se material compreender os motivos pelos quais 'ser negro e negra' no Brasil é vivenciar diuturnamente uma humanidade subalterna, de concessão, que, obviamente, produz subjetividades subalternas alimentadas diariamente pelo racismo que mantém viva a divisão radical entre o universo deste lado da linha e o universo do outro lado da linha, conforme o pensamento abissal de Santos (2010B). Fala-se de uma 'humanidade africana' que continua sendo vilipendiada nas diferentes matizes da colonialidade que se mantém viva, porém com novas formas e roupagens, contribuindo com a manutenção do racismo em nossa sociedade. Portanto, a perspectiva da democracia racial, como afirma Fernandes (2007), não possui consistência na sociedade brasileira e constitui inverdade na medida em que difunde uma relação harmoniosa e igualitária entre grupos raciais, não correspondendo, pois, à realidade vivida pela população de ascendência africana.

No que se refere à construção mundial do racismo, é importante ressaltar a diferença entre o racismo produzido pelo colonizador europeu em relação aos povos africanos e outras formas de relações racistas vivenciadas na história da humanidade. Como conceito básico, sabemos que o racismo pressupõe que um grupo racial - considerando-se o conceito social de raça - considera-se superior a outro grupo racial.

No que se refere ao racismo produzido entre colonizador europeu e povos africanos, a base da relação racista transcende a relação de superioridade/inferioridade, isto é, inclui o antagonismo humanidade/não humanidade. Dito de outro modo, os povos africanos, para o colonoizador europeu, eram mais do que inferiores, eram não humanos. A palavra 'negro' - nome dado pelo colonizador europeu aos africanos - está carregada de valores e ideologia de modo que significa ausência de luz, sem alma. Ou seja, não ter alma implica 'não ser humano', significa ser objeto, ser animal. Portanto, a representação social de 'ser negro e negra' no Brasil tem como base o conceito de não humanidade. Diante de séculos de imersão nessa verdade universal, negros e negras, bem como a sociedade brasileira como um todo, passam a acreditar na não humanidade dos povos de ascendência africana, que, por sua vez, passam a vivenciar uma humanidade de concessão e subalterna, produzindo subjetividades subalternas alimentadas diunturnamente pelo racismo e pelas estratégias de divisão alimentadas por esse mesmo 
racismo. Para Nobles (2009, P. 281) o grande infortuito vivido pelos africanos a partir da colonização europeia está expresso na negação da humanidade africana, "acompanhada do desprezo e do desrespeito, coletivos e contínuos, ao seu direito de existir".

O discurso que foi pronunciado por um escravagista europeu, William Lynch, em 1712 nos dá a dimensão do que foi feito com a existência dos povos de ascendência africana na diáspora. Lynch desenvolveu técnica de controle dos africanos escravizados, que se revoltavam e criavam problemas para os negócios do colonizador escravagista, conforme relata em sua carta:

\section{Senhores:}

Eu saúdo vocês, aqui presentes nas beiras do Rio James, no ano de 1712 do nosso Senhor.

Carlos Nunes Primeiro, devo agradecer a vocês, senhores da colônia da Virgínia, por me trazerem aqui.

Estou aqui para ajudá-los a resolver alguns dos seus problemas com escravos. $\mathrm{O}$ convite de vocês chegou até a mim, lá na minha modesta plantação nas Indias do Oeste onde experimentei alguns mais novos, e outros ainda velhos, métodos de controle de escravos.

A Antiga Roma nos invejaria se o meu programa fosse implementado. Assim que o nosso navio passou ao sul do Rio James, nome do nosso ilustre Rei, eu vi o suficiente para saber que os problemas de vocês não é único.

Enquanto Roma usava cordas e madeira para crucificar grande número de corpos humanos pelas velhas estradas, vocês aqui usam as árvores e cordas. Eu vi um corpo de um escravo morto balançando em um galho de árvore a algumas milhas daqui.

Vocês não estão só perdendo estoques valiosos nesses enforcamentos, estão tendo também levantes, escravos fugindo, suas coIheitas são deixadas no campo tempo demais para um lucro máximo, vocês sofrem incêndios ocasionais, seus animais são mortos. Senhores! Vocês conhecem seus problemas; eu não estou aqui para enumerá-los, mas para ajudar a resolvê-los!

Tenho comigo um método de controle de escravos negros. Eu garanto que se você implementar da maneira certa, controlará os escravos no mínimo durante 300 anos. Meu método é simples e todos os membros da família e empregados brancos podem usá-lo.

Eu seleciono um número de diferenças existentes entre os escravos; eu pego essas diferenças e as faço ficarem maiores, exagero-as. Então eu uso o medo, a desconfiança, a inveja, para controlá-los. Eu usei esse método na minha fazenda e funcionou; não somente lá mas em todo o Sul.

Pegue uma pequena e simples lista de diferenças e pense sobre elas. Na primeira linha da minha lista está 'Idade', mas isso só porque começa com a letra ' $A$ '. A segunda linha, coloquei 'Cor' ou 'Nuances'. Há ainda, 'inteligência', 'tamanho', 'sexo', 'tamanho da plantação', 'status da plantação', 'atitude do dono', 'se mora no vale ou no morro', 'Leste ou Oeste', 'Norte ou Sul', se tem 'cabelo liso ou crespo', se é 'alto ou baixo'.

Agora que você tem uma lista de diferenças, eu darei umas instruções, mas antes, eu devo assegurar que a desconfiança é mais forte do que a confiança e que a inveja é mais forte do que a adulação, o respeito e a admiração.

O escravo negro, após receber esse endoutrinamento ou lavagem cerebral, perpetuará ele mesmo, e desenvolverá esses sentimentos, que influenciarão seu comportamento durante centenas, até milhares de anos, sem que precisemos voltar a intervir. A sua submissão à nós e à nossa civilização será não somente total, mas também profunda e durável.

Não se esqueçam que vocês devem colocar o velho negro contra o jovem negro. E o jovem negro contra o velho negro. Vocês devem jogar o negro de pele escura contra o de pele clara. E o de pele clara contra o de pele escura. O homem negro contra a mulher negra.

É necessário que os escravos confiem e dependam de Nós. Eles devem amar, respeitar e confiar somente em nós.

Senhores, essas dicas são as chaves para 
controlá-los, usem-nas. Façam com que as suas esposas, filhos e empregados brancos também as utilizem. Nunca percam uma oportunidade. Meu plano é garantido e a boa coisa nisso é que se utilizado intensamente durante um ano, os escravos por eles mesmos acentuarão ainda mais essas oposições e nunca mais terão confiança em si mesmos, o que garantirá uma dominação quase eterna sobre eles.

Obrigado, senhores.

William Lynch. (LYNCH, 2012).

Mas o que tudo isso tem a ver com saúde mental? Tem tudo a ver! Afinal, trata-se da constituição de sujeitos, da produção de subjetividades, da construção de identidades do 'ser negro e negra' na diáspora.

A violência a qual os povos de ascendência africana estiveram submetidos no Brasil ao longo de séculos não é apenas a da força bruta, pois o racismo como tipo de violência é exercido, antes de tudo, pela impiedosa tendência de destituir a condição humana de negros e negras. Vilhena (2006) salienta que a população negra, por meio da internalização forçada e brutal dos valores e ideais do branco, é obrigada a adotar modelos incompatíveis com seu próprio corpo, de modo que tal interiorização leva, frequentemente, à alienação e à negação da própria natureza humana, oferecendo como único caminho o embranquecimento físico e/ou cultural. Não obstante, numa perspectiva mais complexa, afirmamos que a população de ascendência africana no Brasil vê-se obrigada a internalizar valores civilizatórios ocidentais e adotar modos de existência antagônicos ao paradigma civilizatório negro-africano, o que, consequentemente, produz sofrimento psíquico.

Bastide (1955 APUDCUCHE, 1999, P. 133), em suas pesquisas sobre o universo da tradição de matriz africana, defendia a ideia de que o africano no Brasil conseguia ser, ao mesmo tempo, fervorosos adeptos da tradição de matriz africana e agentes econômicos perfeitamente adaptados à racionalidade moderna; argumentava que na diáspora o africano passou a viver em dois universos sociais distintos, sem que estes se comunicassem. O que, por sua vez, demonstrava que a aculturação não produzia, necessariamente, "seres híbridos, inadaptados e infelizes"; a essa capacidade Bastide (1955 APUD CUCHE, 1999, P. 133-134) denominou de "princípio de corte". Ou seja, argumentava que o africano que vive em contexto social pluricultural tem a capacidade de cortar "o universo social em um certo número de 'compartimentos isolados' nos quais eles têm 'participações' de ordem diferente que, por isso mesmo, não lhes parecem contraditórios".

No entanto, se num dado contexto social, histórico e cultural os africanos diaspóricos experimentavam com certa tranquilidade os estratagemas da racionalidade moderna, na contemporaneidade observa-se uma situação um pouco diferente. Isto é, se um dia a fragmentação provocada pelo princípio de corte teve função protetiva para a saúde mental dos africanos na diáspora, na contemporaneidade, ele também pode agir como fator desagregador na medida em que os sujeitos não conseguem mais articular aquilo que um dia foi fragmentado; não têm mais consciência dos cortes realizados por seus antepassados (ALVES, 2012).

Viver em dois universos sociais, em duas perspectivas civilizatórias, 'do lado de cá e do lado de lá' simultaneamente, acabou produzindo, hoje, nos africanos da diáspora um sentimento de fragmentação da própria individualidade, da própria identidade cultural. Afinal, não é tarefa fácil, para negros e negras, o exercício de vivenciar, identificar e articular pressupostos filosóficos, éticos e existenciais que sinalizem continuidades e descontinuidades do paradigma civilizatório negro-africano na relação com o paradigma ocidental (ALVES, 2012).

Luz (2000, P. 31) alega que o processo histórico negro-africano é caracterizado por

uma linha de continuidade ininterrupta de determinados princípios e valores 
transcendentes que são capazes de engendrar e estruturar identidades e relações sociais.

Mattos (2003), ao fazer referência à função política e contra-hegemônica da elevação dos valores civilizatórios negro-africanos a redentores da dignidade e identidade negra no Brasil, salienta a necessidade de nos mantermos atentos ao risco de incidirmos nas

armadilhas dos essencialismos, na reprodução não refletida desses valores como conteúdos inalterados de uma tradição supostamente imune às injunções do tempo. (MATTOS, 2003, P. 230).

Bastide (1968, P. 7), ao pôr em discussão as oposições entre civilização ocidental e negro-africana, e ao caracterizá-las a partir da palavra, da linguagem, afirma que uma se constitui a partir do "pensamento por sinais" e a outra, do "pensamento simbólico", ou, ainda, "civilização do sinal" e "civilização do símbolo". Segundo o autor, a primeira "considera a linguagem significativa por si mesma, pela sua gramática, sua sintaxe, suas regras lógicas", de modo que "o sentido não se acha fora das palavras e sim na sua disposição", na sua organização gramatical. Já a segunda, vê nas palavras "a expressão do que se encontra do outro lado do real" e de onde, ele, o real, retira toda a sua realidade. Dito de outra forma, na civilização do sinal (ocidental), a linguagem é concebida "como um objeto exterior que se estuda como uma coisa", já na civilização do símbolo (negro-africana), a linguagem é concebida como uma mensagem.

Desse modo, pensar na saúde mental da população de ascendência africana, da população negra brasileira é adquirir e empregar o impulso revolucionário para atingir a liberdade mental e espiritual (NOBLES, 2009). O que, por sua vez, demanda uma noção de saúde e de saúde mental centrada na humanidade africana. Para tanto, Nobles (2009, P. 281) defende ser necessário que nos interroguemos sobre a linguagem e a lógica dos povos africanos tradicionais para apreender de forma profunda e nítida o funcionamento dos povos africanos contemporâneos.

O autor defende ainda que os ancestrais africanos foram trazidos para o

Novo Mundo destituídos de liberdade, ou seja, em grilhões, mas não chegaram destituídos de pensamento ou crenças sobre quem eles eram.

\section{Os ancestrais africanos}

vieram com uma lógica e uma linguagem de reflexão sobre o que significava ser humano e sobre quem eles eram, a quem pertenciam e por que existiam.

Nobles (2010, P. 281) salienta ainda que

somente por meio de uma interpretação profunda da linguagem e da lógica de nossa própria ancestralidade seremos nós, os africanos diaspóricos.

Afinal, como refere Alves (2012, P. 175), o sujeito que cultua a tradição africana no Brasil

se constitui e se diferencia em sua subjetividade, ao mesmo tempo em que ela é produzida na multiplicidade e unidade da comunidade, dos ancestrais e das divindades.

Trata-se de um sujeito que se constitui e se diferencia a partir de uma base

bio-mítico-social, ou seja, ele é constituído a partir do sentido e significado das divindades e ancestrais, de seus elementos naturais e de sua relação com o coletivo. (ALVES, 2012, P. 175).

Nessa perspectiva, a materialização do princípio da equidade no Sistema Único de Saúde (SUS) só se efetivará a partir do reconhecimento dos diferentes valores e práticas 
civilizatórias que constituem o Estado brasileiro. Afinal, a grande dificuldade da saúde coletiva ocidental é desconstruir a universalidade de seu paradigma civilizatório e, consequentemente, exercitar a dialógica e a alteridade com outras realidades constitutivas de subjetividades e humanidades, numa perspectiva de reparação civilizatória. Afinal, as consequências psicológicas do viver em uma sociedade estruturada pelo racismo são extremamente devastadoras e aniquilantes.

Assim, reafirmamos o paradigma da afrocentricidade como uma perspectiva teórica e prática que inova no campo da saúde coletiva um conceito de humanidade, na medida em que visa a reorientar africanos e suas culturas de uma posição periférica para uma posição centrada, como ressalta Asante (2009), produzindo pesquisa, conhecimento e práticas em saúde a partir dessa epistemologia. A afrocentricidade concebe os africanos e seus descendentes como sujeitos de sua própria ação, sendo que a ideia de conscientização de si está na centralidade, ou seja, africanos e seus descendentes devem operar como agentes autoconscientes de sua história, cuja autodefinição positiva e assertiva deve partir das culturas africanas (MAZAMA, 2009).

\section{Considerações finais}

Compreender, visibilizar, colocar em relevo, positivar, reinterpretar e ressignificar são algumas das muitas palavras que nesse momento emergem e levam à reflexão e problematização sobre coexistência de dois paradigmas civilizatórios que contituem a sociedade brasileira: o ocidental e o negro-africano. Nesse sentido, corroboramos as palavras de Mattos (2003, P. 230) quando defende a "necessidade de edificação de uma cultura política afrodescendente" em nosso País ou, ainda, de:
[...] construir e divulgar concepções e pressupostos capazes de reorientar a nossa compreensão do nosso próprio passado - e, se necessário, mudá-lo na forma como ele se nos mostra - à luz consciente de um projeto político e civilizacional contemporâneo, ao mesmo tempo, emancipador e antirracista. (MATTOS, 2003, P. 231).

O desafio que está posto para a saúde coletiva é o de inaugurar um novo processo de escuta e reconhecimento dos diferentes valores e práticas civilizatórias que constituem a sociedade brasileira. Rompendo, assim, com o olhar preconceituoso e racista que ainda hoje é lançado às pessoas de ascendência africana, bem como com a perspectiva de desagência e de humanidade de concessão e subalterna até então levados a efeito nas relações étnico-raciais de nosso país.

Compreendemos ser necessária a formação de equipes técnicas, políticas e de gestão municiadas do paradigma da afrocentricidade com vistas a protagonizar políticas públicas que tenham como princípio a equidade e a reparação civilizatória. Iniciativa efetivamente inovadora, com impacto político-social no seio da população brasileira, sobretudo na camada da população de ascendência africana. Conforme Nobles (2009, P. 278), "poucas discussões têm articulado com seriedade a natureza fundamental de ser africano", do 'ser negro e negra', "seus significados psicológicos e funções associativos ou a teoria(s) necessária(s) com respeito aos processos psicológicos africanos normais".

Afinal, como defende Fernandes (2007, P. 51),

não poderá haver integração nacional, em bases de um regime democrático, se os diferentes estoques raciais não contarem com oportunidades equivalentes de participação das estruturas nacionais de poder. 


\section{Referências}

ALVES, M. C. Desde dentro: processos de produção de saúde em uma comunidade tradicional de terreiro de matriz africana. 2012. $306 \mathrm{f}$. Tese (Doutorado em Psicologia) - Pontifícia Universidade Católica do Rio Grande do Sul, Faculdade de Psicologia, Rio Grande do Sul, 2012

ASANTE, K. Afrocentricidade: notas sobre uma posição disciplinar. In: NASCIMENTO, E. L. (Org.). Afrocentricidade: uma abordagem epistemológica inovadora. São Paulo: Selo Negro, 2009. p. 93-110.

BASTIDE, R. Religiões africanas e estruturas de civilização. Afro-Ásia. n. 6-7, 1968, p. 5-16. Disponível em: <http://www.afroasia.ufba.br/pdf/afroasia_n6_7_ p5.pdf $>$. Acesso em: 1 mar. 2014.

COMPARATO, F. K. Capitalismo: civilização e poder. Estudos Avançados, São Paulo, v. 25, n. 72, p. 251-276, 2011.

CUCHE, D. A noção de cultura nas ciências sociais. Bauru: UDUSC, 1999.

DUSSEL, E. Ética da libertação: na idade da globalização e da exclusão. 3. ed. Petrópolis: Vozes, 2007.

FERNANDES, F. O negro no mundo dos brancos. 2. ed. São Paulo: Global, 2007.

FERREIRA, R. F.; CAMARGO, A. C. As relações cotidianas e a construção da identidade negra. Psicol. cienc. prof., Brasília, DF, v. 31, n. 2, p. 374-389, 2011.

KUHN, T. A estrutura das revoluções científicas. São Paulo: Perspectiva, 2006.

LYNCH, W. Carta de William Lynch. 2012. Disponível em: <http://comunidademib.blogspot.com.br/2012/10/ carta-de-william-lynch.html>. Acesso em: 24 ago. 2015.

LUZ, M. A. Agadá: dinâmica da civilização africano-brasileira. Salvador: Edufba, 2000.

MATTOS, W. R. Valores civilizatórios afro-brasileiros, políticas educacionais e currículos escolares. Revista da FAEEBA - Educação e Contemporeneidade, v. 12, n. 19, p. 229-234, jan./jun. 2003. Disponível em: <http://www. uneb.br/revistadafaeeba/files/2011/05/numero19.pdf >. Acesso em: 1 abr. 2014.
MAZAMA, A. A afrocentricidade como um paradigma. In: NASCIMENTO, E. L. (Org.). Afrocentricidade: uma abordagem epistemológica inovadora. São Paulo: Selo Negro, 2009. p. 111-128.

MIGNOLO, W. Descolonialidade como o caminho para a cooperação. Revista do Instituto Humanistas Unisinos, n. 431. 2013. Disponível em: <http://www.ihuonline. unisinos.br/index.php?option=com_content\&view=arti cle\&id=5253\&secao=431>. Acesso em: 1 jun. 2014.

MORIN, E. A cabeça bem feita: repensar a reforma, reformar o pensamento. Rio de Janeiro: Bertrand Brasil, 2003.

Ciência com consciência. Rio de Janeiro: Bertrand Brasil, 2002a.

. Introdução ao pensamento complexo. Porto Alegre: Sulina, 2007.

. O método IV: as idéias. Porto Alegre: Sulina, 2002b.

NOBLES, W. Sakhu Sheti: retomando e reapropriando um foco psicológico afrocentrado. In: NASCIMENTO, E. L. (Org.). Afrocentricidade: uma abordagem epistemológica inovadora. São Paulo: Selo Negro, 2009. p. 277-297.

QUIJANO, A. Colonialidade do poder e classificação social. In: SANTOS, B. S.; MENESES, M. P. (Org.). Epistemologias do Sul. São Paulo: Cortez, 2010. p. 84-130.

SANTOS, B. S. Para uma sociologia das ausências e uma sociologia das emergências. In:___ (Org.). Conhecimento prudente para uma vida decente. São Paulo: Cortez, 2006. p. 777-821.

Um ocidente não-ocidentalista! A filosofia à venda, a douta ignorância e a aposta de Pascal. In: SANTOS, B. S.; MENESES, M. P. (Org.). Epistemologias do Sul. São Paulo: Cortez, 2010a. p. 519-562.

Para além do pensamento abissal: das linhas globais a uma ecologia de saberes. In: SANTOS, B. S.; MENESES, M. P. (Org.). Epistemologias do Sul. São Paulo: Cortez, 2010b. p. 31-83. 
Um discurso sobre as ciências. Porto:

Afrontamento, 2002.

SANTOS, J. E. Os nàgô e a morte: Pàde, Àsèsè e o culto Égun na Bahia. Petrópolis: Vozes, 2008.

SILVA, M. L. Racismo e os efeitos na saúde mental. In: BATISTA, L. E.; KALCKMANN, S. (Org.). Seminário Saúde da População Negra Estado de São Paulo 2004. São Paulo: Instituto de Saúde, 2005. p. 129-132.

SODRÉ, M. O terreiro e a cidade: a forma social negro-brasileira. Petrópolis: Vozes, 1988.
VILHENA, J. Violência da cor: sobre racismo, alteridade e intolerância. Revista Psicologia Política, n. 12, v. 6, 2006. Disponível em: <http://www. fafich.ufmg.br/ psicopol/seer/ojs/viewarticle. php?id=7\&layout=html>. Acesso em: 1 jul. 2014.

Recebido para publicação em fevereiro de 2015

Versão final em março de 2015

Conflito de interesses: não houve

Suporte financeiro: inexistente 